\title{
The cryptomonad nucleomorph
}

Geoffrey I. McFadden

School of BioSciences, University of Melbourne, VIC 3010, Australia

\begin{abstract}
The cryptomonad nucleomorph is a vestigial nucleus of a eukaryotic red alga engulfed by a phagotrophic protist and retained as a photosynthetic endosymbiont. This review recounts the initial discovery and subsequent characterization of the cryptomonad nucleomorph focusing on the key role of Peter Sitte and his protégés in our understanding of secondary endosymbiosis to create complex plastids, one of the major transition events in the evolution of life on Earth.
\end{abstract}

Keywords Nucleomorph, cryptomonad, plastid, endosymbiosis 
The first person to see a nucleomorph was apparently British phycologist Dennis Greenwood. Greenwood described structures-which he then termed 'cryptonuclei' - with double membranes, pores, a nucleolar-like region, plus some 'distinctive particles' (Greenwood 1974). Greenwood's article is a one page abstract with just four accompanying microgaphs (Greenwood 1974). Greenwood speculated that 'cryptonuclei' might possibly contain a genophore (genome), and-somewhat remarkably for a one page article - went on to sketch out an hypothesis for the origin of the Chromophyta from a cryptomonad type ancestor via secondary endosymbiosis and loss of the nucleomorph, symbiont starch storage, invention of chlorophyll $c$, and invention of the chloroplast endoplasmic reticulum (cER) (Greenwood 1974). In a subsequent publication, again just an abstract (no micrographs) for a meeting of the British Phycological Society, Greenwood, HB Griffiths and Uwe Santore coined the term 'nucleomorph' to replace 'crypto-nuclei' and again proposed that further reduction of a eukaryotic symbiont contained within cryptomonads (such that the ribosomes, protein synthesis and starch storage in this compartment disappeared) could have given rise to four membrane bound plastids of the Chromophyta (Greenwood et al. 1977).

Two groups confirmed Greenwood's speculation that nucleomorphs contain DNA: one in Canada, and one in Germany. Martha Ludwig - then a PhD student of Sally Gibbs - stained the DNA of Cryptomonas with 4'-6-diamino-2-phenylindole (DAPI) (Ludwig and Gibbs 1985). DAPI accumulates in DNA structure and renders it fluorescent under UV light. Ludwig and Gibbs observed a small genome remote from the main nucleus and estimated that the nucleomorph contained between $10^{8}$ and $10^{9}$ Daltons of DNA on the basis that nucleomorph fluorescent intensity was somewhere between the cryptomonad chloroplast nucleoids and the nucleoids of unidentified bacteria contaminating the culture (Ludwig and Gibbs 1985). Ludwig and Gibbs also made comparisons of 5S rRNA sequences from the databases and concluded that the cryptomonads are not related to other chromophyte algae. So began a now longrunning and still unresolved dispute about the origins of chromophytes: a debate placing cryptomonads at the centre of a very big puzzle in the evolution of life on Earth. 
A German group, led by Peter Sitte from the Cell Biology Department at University of Freiburg, also utilised DAPI to confirm the presence of DNA in nucleomorphs, but they used acrylic sections of cryptomonad cells, providing superior resolution to the Canadian study using whole cells (Hansmann et al. 1985). The two DAPI studies thus confirmed that nucleomorphs contain DNA, corroborating preliminary evidence from regressive DNA staining of a nucleomorph by Uwe Santore (Santore 1982). Sitte's group subsequently produced very elegant images of nucleomorph DNA using immunogold labelling for electron microscopy with an anti-DNA antibody yielding the first ultrastructural localization and showed that the small osmiophylic particles, first observed in nucleomorphs by Greenwood (Greenwood 1974), contain no DNA (Hansmann et al. 1987a). To complement their localization of DNA in the nucleomorph, Paul Hansmann went on to use enzyme gold labelling to demonstrate that the ribosome-like particles observed by Greenwood in the periplasmic space contained RNA (Hansmann 1988). Furthermore, the ribonuclease gold markers also indicated that the enzyme's substrate (RNA) was concentrated in the nucleolus-like (fibrillogranular) body of the nucleomorph and absent from the dense particles (Hansmann 1988). I was then able to show that the RNA in the nucleolus like structure of the cryptomonad nucleomorph and periplastid compartment was eukaryotic type rRNA and not similar in sequence to the plastid rRNAs by using in situ hybridization electron microscopy with Domain specific rRNA probes (McFadden 1990b, a), thereby lending further credence to the notion that the nucleomorph was indeed a miniature nucleus. Immunogold labelling for histones by the Sitte lab was unable to detect these ubiquitous nuclear DNA binding proteins in the nucleomorph, although they were readily detectable in the host nucleus (Hansmann et al. 1987b).

The above mentioned histochemical studies from the Sitte, Gibbs, and McFadden laboratories confirmed Greenwood's surmise that nucleomorphs contained a genome and were essentially miniature nuclei, replete with a nucleolus that encoded rRNAs incorporated into ribosomes in surrounding periplasmic cytoplasm (Greenwood 1974). Meanwhile, morphological studies extended our understanding of nucleomorph size, structure and division. Sitte and Baltes did morphometric calculations to show that whilst the nucleomorph and its surrounding cytoplasm represented only $3 \%$ of the whole cell's translation capacity, the nucleomorph (which 
has a relatively large nucleolus) apparently devotes three times as much of its capacity to ribosome production compared with the host nucleus (Sitte and Baltes 1990).

Division of nucleomorphs was examined by Gillot and Gibbs, Morrall and Greenwood, and McKerracher and Gibbs, with the consensus being that there is one nucleomorph per plastid, the nucleomorph divides before the accompanying plastid, the dividing nucleomorph lacks a mitotic spindle, and the nucleomorph envelope persists throughout division (Gillot and Gibbs 1980; Morrall and Grenwood 1982; McKerracher and Gibbs 1983).

At this point we knew that nucleomorphs contained DNA, and that this DNA encoded eukaryotic rRNAs that were apparently present in ribosomes in the periplasmic cytoplasmic compartment surrounding the nucleomorph. The Holy Grail was now to get our hands on some nucleomorph DNA. Isolating nucleomorph DNA was a challenging quest because 1/ the amount of DNA is miniscule (Ludwig and Gibbs 1985 ), and 2 / volume wise the nucleomorph is a mere $0.3 \%$ of the total volume of the cell (Sitte and Baltes 1990)_a classic needle-in-a-haystack problem. Attempts in Freiburg to separate nucleomorph DNA from the copious amounts of nuclear, plastid and mitochondrial DNA using caesium chloride density gradients were unsuccessful (Hansmann et al. 1987b). But the Freiburg lab ultimately solved this dilemma using a very clever cell fractionation approach to isolate nucleomorphs (Hansmann and Eschbach 1990). By cunningly employing a cryptomonad (Pyrenomonas) in which the nucleomorph is enclosed within the pyrenoid, Hansmann and Stefan Eschbach took advantage of the robustness and high density of pyrenoids to disintegrate Pyrenomonas cells and then centrifugally sediment the nucleomorph-containing pyrenoids on density gradients (Hansmann and Eschbach 1990). This approach yielded the first fraction of nucleomorphs, and DAPI staining estimates provided an astonishingly small (yet remarkably accurate) nucleomorph genome size estimate of just 700kb (Hansmann and Eschbach 1990). The next step was to karyotype isolated nucleomorphs by pulse field gel electrophoresis (able to separate relatively large, chromosome-sized DNA molecules), which gave us the first insight into nucleomorph genome architecture (Eschbach et al. 1991a). The Freiburg team resolved three small linear chromosomes from the Pyrenomonas nucleomorphs, showing that they were indeed reduced nuclei with remarkably small genomes, weighing in at a mere $660 \mathrm{~kb}$ - drastically smaller than the host nucleus and indeed any nucleus then known. 
Sitte's Freiburg team had suddenly thrown open nucleomorph research (Eschbach et al. 1991a), and hence the secrets of secondary endosymbiosis, like never before. My lab quickly adopted the pyrenoid/nucleomorph isolation protocol and we too had three eukaryotic endosymbiont chromosomes staring at us from our agarose gels (McFadden 1993). What did they encode?

1991 proved somewhat of a halcyon year for the nucleomorph. A new team from Canada entered the fray and used PCR to bypass nucleomorph isolation, instead taking advantage of the difference in size between the host and endosymbiont $18 \mathrm{~S}$ rRNA genes to separate and sequence the two amplicons (Douglas et al. 1991). The two gene sequences were incorporated into the emerging rDNA tree of eukaryotes with one (tentatively assigned as originating from the host nucleus) being allied to the plants and green algae, and the other (tentatively assigned as originating from the nucleomorph) being allied to the red algae Gracilaria and Gracilariopsis (Douglas et al. 1991). Recovering two different, evolutionarily distant genes from one cell spectacularly corroborated the hypothesis that cryptomonads harbour a reduced red algal endosymbiont (Douglas et al. 1991). But the Canadian team candidly admitted that evidence that the red algal affiliated gene from their cryptomonad came out of the nucleomorph was lacking (Douglas et al. 1991). The Freiburg team used their isolated nucleomorphs to settle this issue. Sitte's team made Southern blots of their pulsed field gel separated chromosomes from isolated nucleomorphs and showed that all three chromosomes encoded $18 \mathrm{~S}$ and 25S rRNA genes, likely in a classic eukaryotic rRNA cistron (Eschbach et al. 1991a). Eschbach, Wolters and Sitte sequenced the 18S rRNA gene from the host nucleus of Pyrenomnas and modelled the secondary structure and made a phylogeny (Eschbach et al. 1991b). Another Freiburger, Uwe Maier, cut the nucleomorph chromosomes out of pulsed field gels and used PCR to amplify the nucleomorph rRNA gene for sequencing and phylogeny (Maier et al. 1991). The phylogenetic tree was satisfying in the sense that it supported the Canadian study (Douglas et al. 1991) in showing that the nucleomorph 18S rRNA gene was evolutionarily remote from the nuclear gene from the same cell, but the Freiburg analysis provided only weak indications of the ancestry of the nucleomorph positioning it close to four genes from red algae but not clustering them unequivocally (Maier et al. 1991). With hindsight, we now realise that the phylogenetic ancestry of nucleomorph gene is somewhat masked by accelerated divergence; it's a difficult gene 
to infer trees with. I later rounded out these studies by using electron microscope level in situ hybridization with gene-specific probes to prove that transcripts of the nucleomorph rRNA gene are in the nucleolus of the nucleomorph and surrounding periplasmic cytoplasm, while transcripts of the nuclear rRNA gene are in the nucleolus of the host cell nucleus and it surrounding cytoplasm (McFadden et al. 1994). Thus, a blend of electron microscopy, histochemistry, molecular biology and phylogenetics performed across three continents confirmed that nucleomorphs are indeed vestigial nuclei of a red algal eukaryotic endosymbiont. Greenwood was right (Greenwood 1974).

Cryptomonads are inconspicuous and not particularly diverse. They come in a range of colours, but it is fair to say that if you've seen one cryptomonad, you've seen them all. However, their uniformity notwithstanding, the work described above showed that cryptomonads are among the most complicated cells on Earth, being the amalgam of two separate eukaryotes (host and endosymbiont) and two separate prokaryotes (the cyanobacterial like ancestor of their plastid and the $\alpha$-proteobacterial like ancestor of their mitochondrion). Over a beer one evening in a Freiburg Biergarten, Uwe Maier laid out an audacious plan to us. Maier suggested that the previously competing teams from Germany, Canada and Australia should form a consortium and collaborate to sequence a nucleomorph genome. We announced our plan in an article called 'Bonsai Genomics', wherein we extolled the benefits of sequencing the world's smallest nucleus, pruned down by endosymbiosis to a core of eukaryotism (McFadden et al. 1997). By 2000 the team had progressed inwards from the ends of the three nucleomorph chromosomes confirming the presence of canonical (albeit novel) eukaryotic telomeres subtended by rRNA cistrons at the termini of each chromosome (Zauner et al. 2000). It was proposed that the entire repeat was kept identical by a mechanism of concerted evolution across the six ends (Zauner et al. 2000). The interior of the chromosomes carried densely packed protein and tRNA genes that were reminiscent of red algal genes in being almost completely devoid of introns (Zauner et al. 2000). The gene repertoire covered typical eukaryotic housekeeping functions, and two raison d'être genes ( $f t s Z$ and rubredoxin) encoding proteins likely essential for maintenance of the plastid, which explained why the nucleomorph persisted - it encodes crucial information for the maintenance, and biogenesis of the plastid (Zauner et al. 2000). The complete sequence (551,264 base 
pairs) followed in 2001 and showed a residue of just 30 genes for chloroplast maintenance/function scattered among 464 protein coding genes with a wide range of housekeeping functions (Douglas et al. 2001) including canonical histones that Sitte's team were not able to detect histochemically (Hansmann et al. 1987b). The paucity of spliceosomal introns was further confirmed, as was the dense packing of genes consistent with severe pruning of the DNA content during the nucleomorph's tenure as an endosymbiont within the cryptomonad host (Douglas et al. 2001). John Archibald's lab in Canada sequenced several cryptomonad nucleomorphs showing that all had converged on three small chromosomes but that the mechanisms and extent of reductions and repeats varied across the genera (Lane and Archibald 2006; Lane et al. 2007; Tanifuji et al. 2011; Moore et al. 2012).

A crucial insight from the nucleomorph genome was that it lacked many genes for functions considered essential for the maintenance and replication of the nucleomorph and its expression machinery-proteins for this apparatus clearly had to be encoded by the host nucleus and imported into the nucleomorph/periplastid cytoplasm for the cells-within-cells that comprise a cryptomonad to work (Douglas et al. 2001). Herein lay the next major challenge to understand these cellular equivalents of the Russian matryoshka dolls.

Plastid proteins encoded by the nucleomorph must be made in the periplastid space and imported across the two inner cryptomonad plastid membranes. By analogy, it was early reasoned that this would happen by the same mechanism used by the red algal ancestor of the cryptomonad endosymbiont. Indeed, the first two nucleomorph encoded plastid proteins (FtsZ and rubredoxin) bear N-terminal extensions proposed to act as transit peptides (Zauner et al. 2000), as do many of the plastid proteins identified in the whole nucleomorph genome (Douglas et al. 2001). Indeed, two of these putatively targeted proteins (Tic 110 [Iap100] and Tic22) (Douglas et al. 2001) are components of the plant chloroplast import machinery, which is apparently highly conserved across all types of plastids including those of cryptomonads (McFadden and van Dooren 2004).

More puzzling was how proteins from the cryptomonad host nucleus could cross the four membranes bounding these complex plastids. Work with diatoms, which also 
have a CER and were proposed by Greenwood to derive from cryptomonad-like ancestors (Greenwood 1974), showed that host nucleus encoded plastid proteins use classic secretory signal peptides to cross the outermost, ribosome-encrusted plastid membrane (the so-called cER)(Bhaya and Grossman 1991), and similar arguments were made for cryptomonad proteins(Reith 1996). This left the traversal of only one of the four cryptomonad plastid bounding membranes (known as the periplastid membrane and second in from the outermost) as unexplained. Uwe Maier's group solved this conundrum by oing back to first principals. They reasoned that the translocon pore would be a multimembrane pass protein encoded by the nucleomorph (Sommer et al. 2007). From there they were able to demonstrate that cryptomonads employ a translocation motor originally derived from the endosymbiont's ER that has been relocated into the periplastid membrane (Sommer et al. 2007). This translocation system, known as the ER-associated protein degradation (ERAD) translocon, normally extracts misfolded proteins from the ER lumen for degradation in the cytoplasm (Bagola et al. 2010; Mehnert et al. 2010). In other words, the translocation system re-imports proteins back into the cytosol from the lumen of the ER, which is technically an external compartment. This is exactly the direction required for import across the periplastid membrane of the apicoplast, so the ERAD system was apparently ideal for the task. Moreover, the ERAD machinery recognises unfolded proteins, which is a characteristic of plastid targeting transit peptides (Ralph et al. 2004). Maier's team proposed that relocation of the ERAD translocon from the endosymbiont's ER to its plasma membrane, which are effectively continuous, was the critical invention for import of proteins into the secondary plastid (Sommer et al. 2007). Indeed, by simply relocating its ERAD translocon into its plasma membrane, the endosymbiont was apparently able to import proteins from the lumen of the host's ER-the space between the outermost secondary plastid membrane and the periplastid membrane.

Maier refers to the endosymbiont ERAD system as SELMA (symbiont-specific ERAD-like machinery (Hempel et al. 2009). Like canonical ERADs, SELMA comprises multiple components, the identity and roles of which have now been explored in other complex plastids in organisms such as diatoms and apicomplexan parasites, all of which use the SELMA system discovered in the cryptomonad nucleomorph (Gould et al. 2015; Maier et al. 2015; Fellows et al. 2017). 
The SELMA system also traffics host nucleus encoded proteins into the periplastid space and nucleomorph. The routing decision for plastid versus

periplastid/nucleomorph destinations after SELMA translocation is heavily influenced by the newly exposed terminal residue of the transit peptide after signal peptide cleavage (Gould et al. 2006). If this residue is a phenylalanine, the protein typically goes into the plastid via the Toc and Tic machinery. Other residues result predominantly in a periplastid space/nucleomorph localization (Gould et al. 2006).

The collaborative nature of nucleomorph research reached its zenith with the completion of the entire genome (nucleomorph, nucleus, mitochondrion and plastid) (Curtis et al. 2012) for the model cryptomonad Guillardia theta (named after the eminent phycologist Bob Guillard). Peter Sitte had long since retired, but the team he created collaborated with researchers from many countries to complete the work begun in Freiburg three decades ago. Sitte's gentlemanly style brought researchers together to solve big questions: his flair for microscopy and cell biology inspired them to address these questions with the very best tools of the day.

\section{References}

Bagola K, Mehnert M, Jarosch E, Sommer T (2010) Protein dislocation from the ER. Biochim Biophys Acta 1808:925-936

Bhaya D, Grossman A (1991) Targeting proteins to diatom plastids involves transport through an endoplasmic reticulum. Mol. Gen. Genet. 229:400-404

Curtis BA, Tanifuji G, Burki F, Gruber A, Irimia M, Maruyama S, Arias MC, Ball SG, Gile GH, Hirakawa Y, Hopkins JF, Kuo A, Rensing SA, Schmutz J, Symeonidi A, Elias M, Eveleigh RJ, Herman EK, Klute MJ, Nakayama T, Obornik M, ReyesPrieto A, Armbrust EV, Aves SJ, Beiko RG, Coutinho P, Dacks JB, Durnford DG, Fast NM, Green BR, Grisdale CJ, Hempel F, Henrissat B, Hoppner MP, Ishida K, Kim E, Koreny L, Kroth PG, Liu Y, Malik SB, Maier UG, McRose D, Mock T, Neilson JA, Onodera NT, Poole AM, Pritham EJ, Richards TA, Rocap G, Roy SW, 
Sarai C, Schaack S, Shirato S, Slamovits CH, Spencer DF, Suzuki S, Worden AZ, Zauner S, Barry K, Bell C, Bharti AK, Crow JA, Grimwood J, Kramer R, Lindquist E, Lucas S, Salamov A, McFadden GI, Lane CE, Keeling PJ, Gray MW, Grigoriev IV, Archibald JM (2012) Algal genomes reveal evolutionary mosaicism and the fate of nucleomorphs. Nature 492:59-65

Douglas S, Zauner S, Fraunholz M, Beaton M, Penny S, Deng L-T, Wu X, Reith ME, Cavalier-Smith T, Maier U-G (2001) The highly reduced genome of an enslaved algal nucleus. Nature 410:1091-1096

Douglas SE, Murphy CA, Spencer DF, Gray MW (1991) Cryptomonad algae are evolutionary chimaeras of two phylogenetically distinct unicellular eukaryotes. Nature 350:148-151

Eschbach S, Hofmann C, Maier U-G, Sitte P, Hansmann P (1991a) A eukaryotic genome of $660 \mathrm{~kb}$ : electrophoretic karyotype of nucleomorph and cell nucleus of the cryptomonad alga, Pyrenomonas salina. Nucl Acids Res 19:1779-1781

Eschbach S, Wolters J, Sitte P (1991b) Primary and secondary structure of the nuclear small subunit ribosomal RNA of the cryptomonad Pyrenomonas salina as inferred from the gene sequence: Evolutionary implications. J Mol Evol 32:247-252

Fellows JD, Cipriano MJ, Agrawal S, Striepen B (2017) A plastid protein that evolved from ubiquitin and is required for apicoplast protein import in Toxoplasma gondii. MBio 8

Gillot M, Gibbs S (1980) The cryptomonad nucleomorph: Its ultrastructure and evolutionary significance. J Phycol 16:558-568

Gould SB, Maier UG, Martin WF (2015) Protein import and the origin of red complex plastids. Curr Biol 25:R515-521

Gould SB, Sommer MS, Hadfi K, Zauner S, Kroth PG, Maier UG (2006) Protein targeting into the complex plastid of cryptophytes. J Mol Evol 62:674-681 
Greenwood A (1974) The Cryptophyta in relation to phylogeny and photosynthesis. In J Sanders, D Goodchild, eds, 8th international congress of electron microscopy. Australian Academy of Sciences, Canberra, pp 566-567

Greenwood A, Griffiths H, Santore U (1977) Chloroplasts and cell compartments in Cryptophyceae. Br Phycol J 12:119

Hansmann P (1988) Ultrastructural localization of RNA in cryptomonads. Protoplasma 146:81-88

Hansmann P, Eschbach S (1990) Isolation and preliminary characterization of the nucleus and the nucleomorph of a cryptomonad, Pyrenomonas salina. Eur J Cell Biol $52: 373-378$

Hansmann P, Falk H, Scheer U, Sitte P (1987a) Ultrastructural localization of DNA in two Cryptomonas species by use of a new monoclonal DNA antibody. Eur J Cell Biol 42:152-160

Hansmann P, Falk H, Sitte P (1985) Zeitschrift fur Naturforschung 40c:933-935

Hansmann P, Maerz M, Sitte P (1987b) Investigations on genomes and nucleic acids in cryptomonads. Endocyt C Res 4:289-295

Hempel F, Bullmann L, Lau J, Zauner S, Maier UG (2009) ERAD-derived preprotein transport across the second outermost plastid membrane of diatoms. Mol Biol Evol $26: 1781-1790$

Lane CE, Archibald JM (2006) Novel nucleomorph genome architecture in the cryptomonad genus Hemiselmis. J Eukaryot Microbiol 53:515-521

Lane CE, van den Heuvel K, Kozera C, Curtis BA, Parsons BJ, Bowman S, Archibald JM (2007) Nucleomorph genome of Hemiselmis andersenii reveals complete intron 
loss and compaction as a driver of protein structure and function. Proc Natl Acad Sci U S A 104:19908-19913

Ludwig M, Gibbs S (1985) DNA is present in the nucleomorph of cryptomonads: further evidence that the chloroplast evolved from a eukaryotic endosymbiont. Protoplasma 127:9-20

Maier U-G, Hofmann C, Eschbach S, Wolters J, Igloi G (1991) Demonstration of nucleomorph-encoded eukaryotic small subunit ribosomal RNA in cryptomonads. Mol Gen Genet 230:155-160

Maier UG, Zauner S, Hempel F (2015) Protein import into complex plastids: Cellular organization of higher complexity. Eur J Cell Biol 94:340-348

McFadden GI (1990a) Evidence that cryptomonad chloroplasts evolved from photosynthetic eukaryotic endosymbionts. J Cell Sci 95:303-308

McFadden GI (1990b) Evolution of algal plastids from eukaryotic endosymbionts. In N Harris, D Wilkinson, eds, In situ hybridization: applications to developmental biology and medicine. Cambridge University Press, Cambridge, pp 143-156.

McFadden GI (1993) Second-hand chloroplasts: evolution of cryptomonad algae. Adv. Bot. Res. 19:189-230

McFadden GI, Gilson PR, Douglas SE (1994) The photosynthetic endosymbiont in cryptomonad cells produces both chloroplast and cytoplasmic-type ribosomes. J Cell Sci 107:649-657

McFadden GI, Gilson PR, Douglas SE, Hofmann CJB, Maier U-G (1997) Bonsai genomics: Sequencing the smallest eukaryotic genomes. Trends Genet. 13:46-49

McFadden GI, van Dooren GG (2004) Evolution: red algal genome affirms a common origin of all plastids. Curr. Biol. 14:R514-516 
McKerracher L, Gibbs SP (1983) Cell and nucleomorph division in the alga

Cryptomonas. Can J Bot 60:2440-2452

Mehnert M, Sommer T, Jarosch E (2010) ERAD ubiquitin ligases: multifunctional tools for protein quality control and waste disposal in the endoplasmic reticulum. Bioessays

Moore CE, Curtis B, Mills T, Tanifuji G, Archibald JM (2012) Nucleomorph genome sequence of the cryptophyte alga Chroomonas mesostigmatica CCMP1168 reveals lineage-specific gene loss and genome complexity. Genome Biol Evol 4:1162-1175

Morrall S, Grenwood AD (1982) Ultastructure of nucleomorph division in species of Cryptophyceae and its evolutionary implications. J. Cell Sci. 54:311-328

Ralph SA, Foth BJ, Hall N, McFadden GI (2004) Evolutionary pressures on apicoplast transit peptides. Mol Biol Evol 21:2183-2194

Reith M (1996) The evolution of plastids and photosynthetic apparatus. In D Ort, C Yocum, eds, Oxygenic photosynthesis: the light reactions. Kluwer Academic Publishers, Netherlands, pp 643-657

Santore U (1982) The distribution of the nucleomorph. Cell Biol Int Rep 6:1055-1063

Sitte P, Baltes S (1990) Morphometric analyis of two cryptomonads. Quantitative evaluation of fine-structural changes in an endocytobiotic system. Endocytobiology 6:229-233

Sommer MS, Gould SB, Lehmann P, Gruber A, Przyborski JM, Maier UG (2007)

Der1-mediated preprotein import into the periplastid compartment of chromalveolates? Mol Biol Evol 24:918-928

Tanifuji G, Onodera NT, Wheeler TJ, Dlutek M, Donaher N, Archibald JM (2011) Complete nucleomorph genome sequence of the nonphotosynthetic alga Cryptomonas paramecium reveals a core nucleomorph gene set. Genome Biol Evol 3:44-54 
Zauner S, Fraunholz M, Wastl J, Penny S, Beaton M, Cavalier-Smith T, Maier U-G, Douglas S (2000) Chloropast protein and centrosomal genes, a tRNA intron, and odd telomeres in an unusually compact eukaryotic genome, the cryptomonad nucleomorph. Proc. Natl Acad. Sci. USA 97:200-205 


\section{University Library}

\section{- M M N E R VA A gateway to Melbourne's research publications}

Minerva Access is the Institutional Repository of The University of Melbourne

Author/s:

McFadden, GI

Title:

The cryptomonad nucleomorph

Date:

2017-09-01

Citation:

McFadden, G. I. (2017). The cryptomonad nucleomorph. PROTOPLASMA, 254 (5), pp.1903-1907. https://doi.org/10.1007/s00709-017-1153-5.

Persistent Link:

http://hdl.handle.net/11343/282648 